\title{
Evaluating the potential use of electronic tongue in early identification and diagnosis of bacterial infections
}

Rowa' Al Ramahi'

Abdel Naser Zaid'

Nawaf Abu-Khalaf ${ }^{2}$

'Pharmacy Department, Faculty of Medicine and Health Sciences, An-Najah National University, Nablus, Palestine; ${ }^{2}$ Department of Agricultural Biotechnology, College of Agricultural Sciences and Technology, Palestine Technical University-Kadoorie (PTUK), Tulkarm, Palestine
Correspondence: Rowa' Al Ramahi Pharmacy Department, Faculty of

Medicine and Health Sciences, An-Najah National University, P.O.Box (7), Nablus, Palestine

Tel +97292345II3

Email rawa_ramahi@najah.edu
This article was published in the following Dove Press journal: Infection and Drug Resistance

Background: Electronic tongue (ET) is a simple device that may have some applications in the medical field as an alternative tool to traditional diagnostic methods. The aim of this study is to evaluate the potential use and accuracy of ET in the diagnosis of certain bacterial infections.

Methods: An alpha-Astree ET was used for the detection of known bacterial strains Staphylococcus aureus (ATCC 25923), Escherichia coli (ATCC 25922), and Pseudomonas aeruginosa (ATCC 27853) which were tested at three-time intervals; 15, 18, and $24 \mathrm{hrs} \mathrm{(hr).}$ This was used to build a qualitative and quantitative mathematical model to detect the presence of bacteria at the earliest possible time. When the model is robust, new unknown samples were tested after $15 \mathrm{hrs}$ of bacterial growth. Samples were identified using multivariate data analysis techniques.

Results: Principal Component Analysis (PCA) scores showed that ET can distinguish between the three bacteria at different times 15, 18, and 24 hrs using different sensors. In the PCA scores plots, the discrimination index was $83 \%$ at $15 \mathrm{hrs}, 88 \%$ at $18 \mathrm{hrs}$, and $96 \%$ at $24 \mathrm{hrs}$, the variances explained by the two principal components were $84 \%, 99 \%$, and $97 \%$ at 15,18 , and $24 \mathrm{hrs}$, respectively. Fifteen hours was the earliest time at which the bacteria could be detected. Then six samples of E.coli (as unknown samples) were tested after $15 \mathrm{hrs}$ of inoculation, the two discrimination function explained about $100 \%$ of the variance (ie, $79.7+22.3 \%$ ) and all unknown samples were identified as E.coli.

Conclusion: ET could differentiate between types of bacteria in addition to identifying unknown bacterial cultures (E. coli) at times shorter than that required in the current culturebased methods (24-48 hrs), this could be of a great value in early diagnosis of lifethreatening infections

Keywords: electronic tongue, sensors, bacteria, diagnosis

\section{Introduction}

Early diagnosis of bacterial infections is very crucial and can be life-saving. Accurate diagnosis is important to avoid unnecessary antibiotic use and give the suitable treatment as soon as possible, this requires combining signs and symptoms with diagnostic tests to determine the causative pathogen. ${ }^{1}$ Methods used in the diagnosis of some diseases can be expensive, inconvenient, time-consuming, and even invasive. If new and easier methods in diagnosis are found, this would be of great benefit for the whole therapeutic process. Some rapid diagnostic tests are available as antigen testing, but they are not highly sensitive, so they cannot be relied on to exclude infections. ${ }^{1}$ In recent years, some infection markers have been 
used to confirm the presence of bacterial infections, such as procalcitonin, C-reactive protein, and interleukins, these markers can tell if there is a bacterial infection or not, but unfortunately they cannot identify the causative agent. ${ }^{2,3} \mathrm{~A}$ possible promising alternative to the traditional diagnostic methods is in the electronic sensors; such as electronic nose (EN) and electronic tongue (ET) which are devices that try to mimic the human smell and taste sensors (gas and liquid sensors) and their communication with the human brain. ${ }^{4}$ Recently, these devices have been used for different applications in food and pharmaceutical industries as the analysis of medication taste and odor, comparison between pharmaceutical products in taste, assessing quality of medicinal and aromatic plant products and quality control of edible oils. ${ }^{5-8}$

The use of ET in medical diagnosis might be promising. Because EN which is similar in its principle to ET has been tested for this use in several studies and the results were satisfying. EN is based on arrays of different sensor types that respond to specific features of an odorant molecule, mostly volatile organic compounds, it has shown promising results in the diagnosis and/or screening of various respiratory and systemic diseases by evaluating the odor of different samples of exhaled breath. ${ }^{9}$ Bacterial cultures usually require $24-48 \mathrm{hrs}(\mathrm{hr})$ to grow the pathogen and obtain a pure culture for further testing. Therefore, the shorting of this period as much as possible would be of great value for many physicians, medical laboratories, and patients. To the best of our knowledge, there are no available data in the literature about the use of ET in bacterial identification in suspected human bacterial infections. ET may be useful for detection of bacterial contamination or diagnosis of infections, if minimal standards of selectivity and sensitivity can be met. The objectives of this study are to assess the suitability of ET in the diagnosis of some bacterial infections and to find the minimum time required for the detection of the causative organism.

\section{Materials and methods}

\section{Media culture preparation}

Nutrient agar (NA) was used for the cultivation of bacterial isolates. The media was prepared by weighting $23 \mathrm{~g}$ of NA powder that was dissolved completely in $1 \mathrm{~L}$ of distilled water (DW) with heating. Then, the solution was sterilized by autoclaving at $121^{\circ} \mathrm{C}$ and 15 psi for 15 mins. After sterilization, the agar solution was cooled and poured in $9 \mathrm{~cm}$ petri dishes under microbiological safety cabinet (MN 120) and stored in a refrigerator.

Meanwhile, Nutrient broth (NB) was used for bacterial growth for ET measurements. The media was prepared by weighting $13 \mathrm{~g}$ of NB powder that was dissolved completely in $1 \mathrm{~L}$ of DW by heating. The solution was then suspended in $250 \mathrm{~mL}$ flasks, each flask contained 100 $\mathrm{mL}$ of the media that was autoclaved sterilized at $121^{\circ} \mathrm{C}$ and 15 psi for 15 mins and used for bacterial growth.

\section{Bacteria sample preparation}

Three bacteria isolates were used in this study, Escherichia coli, Staphylococcus aureus, and Pseudomonas aeruginosa, which are common pathological causes for infectious diseases in humans. Bacterial strains were obtained from the American Type Culture Collection (ATCC) including S. aureus (ATCC 25923), E. coli (ATCC 25922), and P. aeruginosa (ATCC 27853) The three bacteria were cultivated on prepared plates using cotton swab. The swabbed parties were labeled, sealed, and incubated for $24 \mathrm{hrs}$ at $37^{\circ} \mathrm{C}$. Then, fresh colonies (approximately $154 * 10^{-7} \mathrm{CFU}$ ) from the cultivated bacteria were transferred to $250 \mathrm{~mL}$ flasks containing $100 \mathrm{~mL}$ NB. The inculcated flasks were then incubated at $37^{\circ} \mathrm{C}$ with shaking at $150 \mathrm{rpm}$ for different time periods.

\section{ET measurements of bacterial samples}

An alpha-astree ET device (Alpha MOS, Toulouse, France) was used for the experiment. It is composed of a seven sensors array; their measurements are based on the potentiometric principle. The ET is equipped with a 16position auto-sampler, an automatic stirrer and an $\mathrm{Ag} /$ $\mathrm{AgCl}$ reference electrode. It has seven solid potential sensors that are chemically modified field effect transistors designated by the manufacturer as $\mathrm{BA}, \mathrm{BB}, \mathrm{GA}, \mathrm{CA} \mathrm{JB}$, $\mathrm{HA}$, and $\mathrm{ZZ}$, in addition to the $\mathrm{Ag} / \mathrm{AgCl}$ reference electrode. These sensors consist of two parts: the sensitive layer and the transducer. These sensors are coated with specific membrane (chemical compounds) to induce both cross sensitivity and cross selectivity. A reversible bond will form between specific molecules and the coated membrane leading to variation in potential between each sensor and $\mathrm{Ag} / \mathrm{AgCl}$ reference electrode. ${ }^{10}$ The device has also a software package for multivariate data analysis (chemometrics) named AlphaSoft software (Alpha MOS, Toulouse, France), which automatically collects and stores the sensors' outputs signal and presents the results as figures (Alpha MOS, 2009). 
Grown bacterial isolates were tested after 18, 20, 22, and $24 \mathrm{hrs}$ of inoculation, where the NB of each bacterial isolates was filtrated using white cheese cloth obtaining an approximate volume of $100 \mathrm{~mL}$. Then, the filtrated broth was powered in $100 \mathrm{~mL}$ beaker and placed on the autosampler according to the created method and sequence for this experiment (applying the alpha MOS manual instructions). The results of this part were not included here in order not to have a large number of figures and as this step was performed to know if we can continue or not. As the device was able to identify each bacterial isolate at the four times included, we decided to repeat the experiment at 24 and $18 \mathrm{hrs}$ and try it at a shorter time after $15 \mathrm{hrs}$ of inoculation following the same methodology.

After that, unknown samples of one of these isolates were tested after $15 \mathrm{hrs}$ of inoculation to find if the ET will be able to recognize it or not.

Principle Component Analysis (PCA) - which is a well-known method that is used with different types of odor and taste sensors $-{ }^{11}$ was used for data exploration and discrimination study, and Discrimination Function Analysis - which is probably the most frequently used pattern recognition method $-{ }^{11}$ was used for sample group projection and identification.

\section{Results}

PCA scores plots (which explain the relationship between samples) showed that ET could distinguish between $E$. coli, S. aureus, and P. aeruginosa at different times 15, 18, and $24 \mathrm{hrs}$ using different sensors. At 15 and $18 \mathrm{hrs}$ of tested period, sensors $\mathrm{ZZ}, \mathrm{BB}$, and $\mathrm{HA}$ were the most discriminative sensors, while at $24 \mathrm{hrs}, \mathrm{ZZ}, \mathrm{JE}, \mathrm{GA}$, and HA were with the highest discriminative power. In all the PCA scores plots, four distinct groups corresponding to the three bacteria species and the control could be easily identified, the discrimination index was $83 \%$ at $15 \mathrm{hrs}$ (Figure 1), 88\% at $18 \mathrm{hrs}$ (Figure 2), and $96 \%$ at $24 \mathrm{hrs}$ (Figure 3). The variances explained by the two principal components were $84 \%, 99 \%$, and $97 \%$ at 15,18 , and 24 hrs, respectively. It is clear that the device could identify bacteria before stationary phase of bacterial growth at 24 hrs. According to this important and promising finding, we decided to go forward to the next step in order to identify an unknown bacterial samples, the experiment was

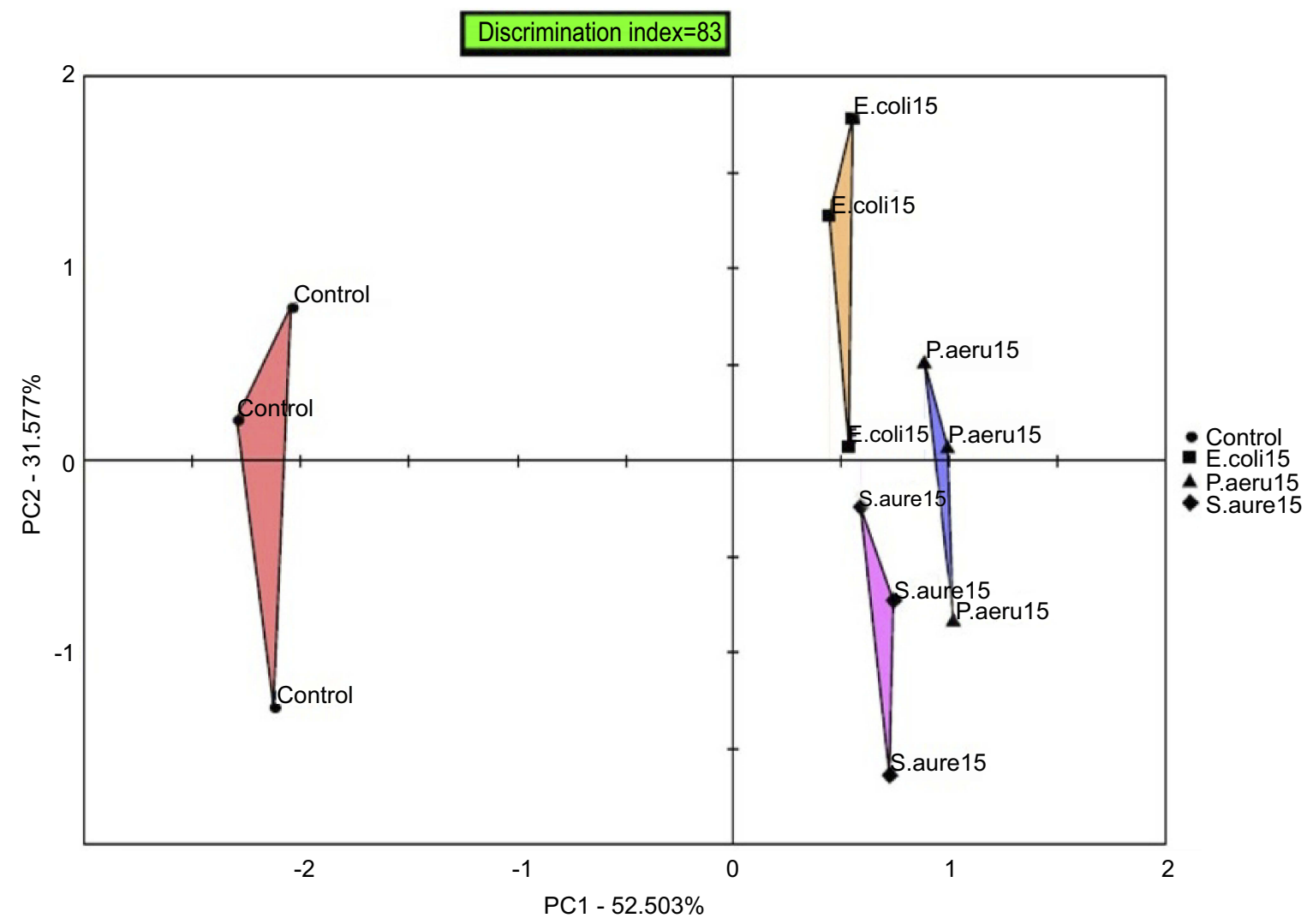

Figure I PCA scores plot of bacterial isolates (Escherichia coli, Staphylococcus aureus, and Pseudomonas aeruginosa) after 15 hrs of inoculation, showing high discrimination index value of 83 between samples. PCI and PC2 explain $84 \%$ of the total variation.

Abbreviation: PCA, Principal Component Analysis. 


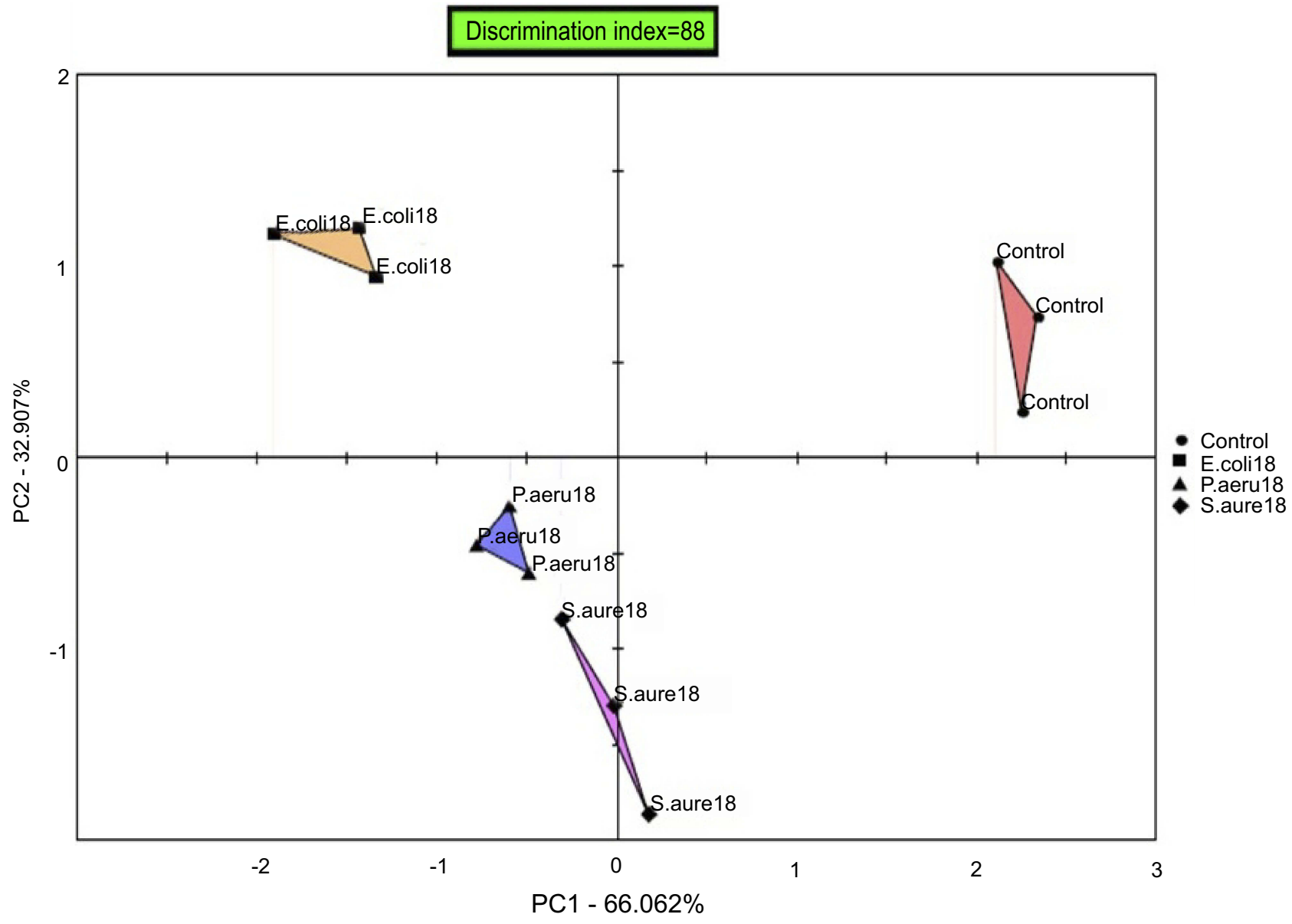

Figure 2 PCA scores plot of bacterial isolates (Escherichia coli, Staphylococcus aureus, and Pseudomonas aeruginosa) after 18 hrs of inoculation, showing high discrimination index value of 88 between samples. PCI and PC2 explain $99 \%$ of the total variation.

Abbreviation: PCA, Principal Component Analysis.

repeated at $15 \mathrm{hrs}$, the minimum time at which the bacteria could be identified in the first part of the study, where six E. coli samples were used (as unknown samples) for this purpose, all data were used (control, 15, 18, $24 \mathrm{hrs)} \mathrm{to}$ build the DAF model (3 types of bacteria at 3 situations $=15$ samples/each case) (Figure 4A). Two sensors where used: $\mathrm{ZZ}$ and $\mathrm{BB}$, the two discrimination function explained about $100 \%$ of the variance (ie, $79.7+22.3 \%$ ) and all unknown samples were identified by the device as E. coli group as they were very close to the position of E. coli after $15 \mathrm{hrs}$ in the DAF model (Figure 4B).

\section{Discussion}

In this study, early identification of bacteria was possible using ET. ET was able to cluster different bacteria groups at $15 \mathrm{hrs}$; this time is shorter than the current traditional methods which require at least $24 \mathrm{hrs}$. This is promising and shows that ET can be used for early screening and diagnosis. In life-threatening infections as sepsis, hours can be life-saving and early administration of suitable antibiotics can decrease mortality. ${ }^{12}$ In previous studies, $\mathrm{EN}$, which is similar in principle to ET was tested for detection of bacterial contamination or diagnosis of infections. Different bacteria produce different odors, so the EN was able to discriminate between a culture of Enterobacter aerogenes and a culture of $E$. coli in one study, ${ }^{13}$ and between P. aeruginosa and Shigella cultured on different media agar in another. ${ }^{14}$ In a study by Carey et al, rapid identification of bacteria grown on standard agar has been achieved from the volatiles they produce using a disposable colorimetric sensor array in a Petri dish imaged with an inexpensive scanner. All ten strains of bacteria tested were identified with $98.8 \%$ accuracy within $10 \mathrm{hrs} .{ }^{15}$ To the best of our knowledge, this is the first study to use ET based on the principle that different bacteria have different components and metabolites, so they are expected to have different tastes that can be distinguished by sensitive sensors of the ET. ET is defined as 


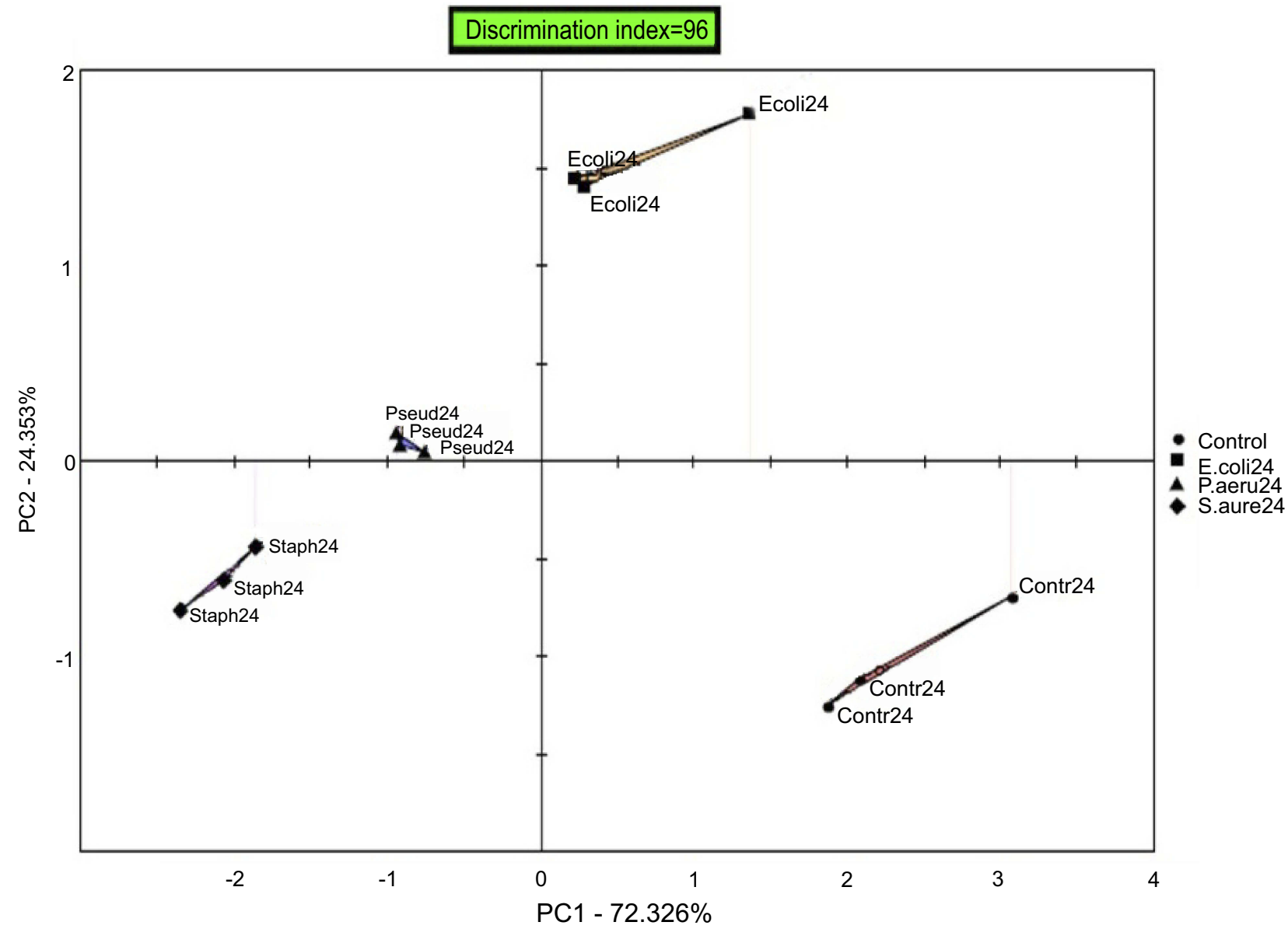

Figure 3 PCA scores plot of bacterial isolates (Escherichia coli, Staphylococcus aureus, and Pseudomonas aeruginosa) after 24 hrs of inoculation, showing high discrimination index value of 96 between samples. $\mathrm{PCl}$ and $\mathrm{PC} 2$ explain $97 \%$ of the total variation.

Abbreviation: PCA, Principal Component Analysis.
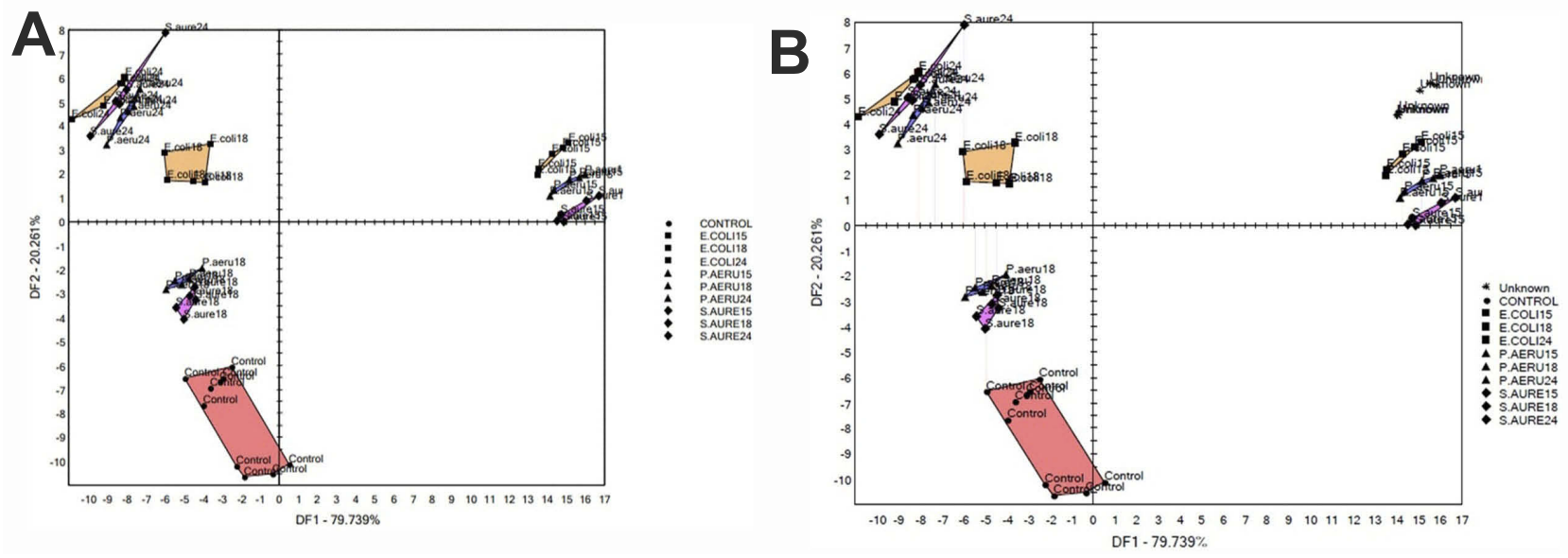

Figure 4 (A) DFA scores plot of bacterial isolates (Escherichia coli, Staphylococcus aureus, and Pseudomonas aeruginosa) after 15, 18, and 24 hrs of inoculation, (B) DFA model showing the projection and identification of unknown bacterial isolates near to $E$.coli. DFI and DF2 explain $100 \%$ of the total variation.

a multi-sensor system, which consists of a number of lowselective sensors and uses advanced mathematical procedures for signal processing based on Pattern Recognition and/or Multivariate data analysis - Artificial Neural Networks (ANNs), Principal Component Analysis (PCA), and so forth. ${ }^{16}$ 
In fact, the ET has been used with success in many applications as in the detection of adulation of oils, for example in a study by Bougrini et al, ET was able to discriminate and classify the argan oil adulterated with different proportions of sunflower oil, ${ }^{11}$ ET has been tested for monitoring quality of foods as milk, taste sensor was capable to discriminate reliably between fresh and spoiled milk and to follow the deterioration of the milk quality when it was stored at room temperature based on PCA ${ }^{17}$ and taste of pharmaceutical products as it can be used in taste masking of products, ${ }^{18}$ or differentiation between the taste of different products. ${ }^{7}$ In the medical field, ET has been tried to test different biological fluids as urine, serum, and sweat; ${ }^{18}$ detection of urinary system dysfunctions and creatinine levels in urine was possible using ET, in one study, the creatinine contents in 51 urine specimens evaluated by ET were compared with those obtained by automated Jaffe's method and GC-MS showed a satisfying agreement for both methods. ${ }^{19}$ Analysis of dialysate fluids during hemodialysis is another possible use, ET was used for the measurements of dialysate fluids containing creatinine and urea additives at concentrations commonly present in post-dialysate fluids. The device was capable of determining urea and creatinine in the range of concentrations (3-12 and 0.10-0.32 $\mathrm{mmol} / \mathrm{L}$ for urea and creatinine, respectively). ${ }^{20}$ In all these applications, ET was an excellent and promising tool. Here also, in this study, the results look promising and further studies are recommended.

Limitations of the study include the use of three types of bacteria only and using high inoculum concentrations. Other studies are recommended in the future to find the lowest concentration of bacteria that the device could identify.

\section{Conclusion}

Differentiation between different types of bacteria in addition to identifying unknown bacteria was achieved using ET. The findings of this study have shown that the ET could identify bacterial cultures at times shorter than that required in current classical culture-based methods; this could be of a value in early diagnosis of life-threatening infections. In addition, this is the first study that opens the door toward a new use of ET in the medical field. Future studies are recommended in order to extend these finding on new types of bacteria. Moreover, additional studies are need to be carried out on patient's samples in order to verify its effectiveness in the clinical field.

\section{Data sharing statement}

The data used to support the findings of this study are available from the corresponding author upon request.

\section{Acknowledgment}

The authors would like to thank the Palestinian Ministry of Higher Education and An-Najah National University for funding of this research.

\section{Disclosure}

The authors declare that they have no conflicts of interest in this work.

\section{References}

1. Boyles TH, Wasserman S. Diagnosis of bacterial infection. South Afr Med J. 2015;105(4):419. doi:10.7196/SAMJ.9647

2. Volante E, Moretti S, Pisani F, Bevilacqua G. Early diagnosis of bacterial infection in the neonate. J Matern Fetal Neonatal Med. 2004;16(Supp12):13-16. doi:10.1080/jmf.16.2.13.16

3. Gao L, Liu X, Zhang D, et al. Early diagnosis of bacterial infection in patients with septicopyemia by laboratory analysis of PCT, CRP and IL-6. Exp Ther Med. 2017;13(6):3479-3483. doi:10.3892/etm.2017. 4417

4. Baldwin EA, Bai J, Plotto A, Dea S. Electronic noses and tongues: applications for the food and pharmaceutical industries. Sensors (Basel). 2011;11(5):4744-4766. doi:10.3390/s110504744

5. Schiffman SS, Kermani BG, Nagle HT. Analysis of medication offodors using an electronic nose. Chem Senses. 1997;22(2):119-128. doi:10.1093/chemse/22.2.119

6. Kiani S, Minaei S, Ghasemi-Varnamkhasti M. Application of electronic nose systems for assessing quality of medicinal and aromatic plant products: a review. $J$ Appl Res Med Aromat Plants. 2016;3 (1):1-9. doi:10.1016/j.jarmap.2015.12.002

7. Abu-Khalaf N, Zaid AN, Jaradat N, et al. The taste of commercially available clarithromycin oral pharmaceutical suspensions in the Palestinian market: electronic tongue and in vivo evaluation. Sensors (Basel). 2018;18:454. doi:10.3390/s18020454

8. Di Rosa AR, Leone F, Cheli F, Chiofalo V. Fusion of electronic nose, electronic tongue and computer vision for animal source food authentication and quality assessment - a review. J Food Eng. 2017;210:6275. doi:10.1016/j.jfoodeng.2017.04.024

9. Lewis JM, Savage RS, Beeching NJ, et al. Identifying volatile metabolite signatures for the diagnosis of bacterial respiratory tract infection using electronic nose technology: a pilot study. PLoS One. 2017;12(12):e0188879. doi:10.1371/journal.pone.01888 79

10. Haraguchi T, Yoshida M, Kojima H, Uchida T. Usefulness and limitations of taste sensors in the evaluation of palatability and taste-masking in oral dosage forms. Asian J Pharm Sci. 2016;11 (4):479-485. doi:10.1016/j.ajps.2016.03.001

11. Bougrini M, Tahri K, Haddi Z, et al. Detection of adulteration in argan oil by using an electronic nose and a voltammetric electronic tongue. J Sens. 2014;245831:10.

12. Seymour CW, Gesten F, Prescott HC, et al. Time to treatment and mortality during mandated emergency care for sepsis. $N$ Engl J Med. 2017;376(23):2235-2244. doi:10.1056/NEJMoa1703058

13. McEntegarta CM, Penrose WR, Strathman S, Stette JR. Detection and discrimination of coliform bacteria with gas sensor arrays. Sens Actautors B. 2000;70(1-3):170-173. doi:10.1016/S0925-4005(00) 00561-X 
14. Zulkifli SA, Mohamad CWSR, Abdullah AH. Classification of Human Pathogen Bacteria for Early Screening Using Electronic Nose. In the 2nd International Conference on Applied Science and Technology. NY: American Institute of Physics; 2017.

15. Carey JR, Suslick KS, Hulkower KI, et al. Rapid identification of bacteria with a disposable colorimetric sensing array. J Am Chem Soc. 2011;133(19):7571-7576. doi:10.1021/ja201634d

16. Valle M. Sensor arrays and electronic tongue systems. Int J Electrochem. 2012;2012:Article ID 986025, 11. doi:10.1155/2012/986025

17. Sim MYM, Shya TJ, Ahmad MN, Shakaff AY, Othman AR, Hitam MS. Monitoring of milk quality with disposable taste sensor. Sensors. 2003;3(9):340-349. doi:10.3390/s30900340
18. Podrażka M, Bączyńska E, Kundys M, Jeleń PS, Nery EW. Electronic tongue - a tool for all tastes? Biosensors. 2017;8(1):3. doi:10.3390/bios 8010003

19. Lvova L, Martinelli E, Dini F, et al. Clinical analysis of human urine by means of potentiometric electronic tongue. Talanta. 2009;77 (3):1097-1104. doi:10.1016/j.talanta.2008.08.021

20. Ciosek P, Grabowska I, Brzózka Z, Wróblewski W. Analysis of dialysate fluids with the use of a potentiometric electronic tongue. Microchim Acta. 2008;163:139-145. doi:10.1007/s00604-007-09 $05-\mathrm{x}$

\section{Publish your work in this journal}

Infection and Drug Resistance is an international, peer-reviewed openaccess journal that focuses on the optimal treatment of infection (bacterial, fungal and viral) and the development and institution of preventive strategies to minimize the development and spread of resistance. The journal is specifically concerned with the epidemiology of antibiotic resistance and the mechanisms of resistance development and diffusion in both hospitals and the community. The manuscript management system is completely online and includes a very quick and fair peerreview system, which is all easy to use. Visit http://www.dovepress.com/ testimonials.php to read real quotes from published authors. 